\title{
Choline supplementation and measures of choline and betaine status: a randomised, controlled trial in postmenopausal women
}

\author{
Julie M. W. Wallace ${ }^{1 *}$, Jacqueline M. McCormack ${ }^{1}$, Helene McNulty $^{1}$, Paula M. Walsh ${ }^{1}$, Paula J. Robson ${ }^{2}$, \\ Maxine P. Bonham ${ }^{3}$, Maresa E. Duffy ${ }^{1}$, Mary Ward ${ }^{1}$, Anne M. Molloy ${ }^{4}$, John M. Scott ${ }^{4}$, Per M. Ueland ${ }^{5}$ \\ and J. J. Strain ${ }^{1}$ \\ ${ }^{1}$ Northern Ireland Centre for Food and Health (NICHE), University of Ulster, Coleraine, County Londonderry BT52 1SA, UK \\ ${ }^{2}$ Division of Population Health and Information, Alberta Cancer Board, Edmonton, AB, Canada \\ ${ }^{3}$ Department of Nutrition and Dietetics, Monash University, Clayton, VIC, Australia \\ ${ }^{4}$ Department of Clinical Medicine and School of Biochemistry and Immunology, Trinity College Dublin, Dublin, \\ Republic of Ireland \\ ${ }^{5}$ Section for Pharmacology, Institute of Medicine, University of Bergen, and Haukeland University Hospital, Bergen, Norway
}

(Submitted 30 June 2011 - Final revision received 1 November 2011 - Accepted 8 November 2011 - First published online 15 December 2011)

\begin{abstract}
Choline is an essential nutrient and can also be obtained by de novo synthesis via an oestrogen responsive pathway. Choline can be oxidised to the methyl donor betaine, with short-term supplementation reported to lower plasma total homocysteine (tHcy); however, the effects of longer-term choline supplementation are less clear. We investigated the effect of choline supplementation on plasma concentrations of free choline, betaine and tHcy and B-vitamin status in postmenopausal women, a group more susceptible to low choline status. We also assessed whether supplementation altered plasma lipid profiles. In this randomised, double-blinded, placebo-controlled study, forty-two healthy postmenopausal women received $1 \mathrm{~g}$ choline per $\mathrm{d}$ (as choline bitartrate), or an identical placebo supplement with their habitual diet. Fasting blood samples were collected at baseline, week 6 and week 12. Administration of choline increased median choline and betaine concentrations in plasma, with significant effects evident after 6 weeks of supplementation $(P<0 \cdot 001)$ and remaining significant at 12 weeks $(P<0.001)$; no effect was observed on folate status or on plasma lipids. Choline supplementation induced a median (25th, 75th percentile) change in plasma tHcy concentration at week 6 of $-0.9(-1 \cdot 6,0 \cdot 2) \mu$ mol, a change which, when compared to that observed in the placebo group $0.6(-0 \cdot 4,1.9) \mu \mathrm{mol}$, approached statistical significance $(P=0 \cdot 058)$. Choline supplementation at a dose of $1 \mathrm{~g} / \mathrm{d}$ significantly increases the circulating concentration of free choline, and can also significantly increase the concentration of the methyl donor, betaine, thereby potentially enhancing the betaine-homocysteine methyltransferase-mediated remethylation of tHcy. This trial was registered at http://www.controlled-trials.com/ISRCTN82708510.
\end{abstract}

Key words: Choline supplementation: Betaine: Homocysteine: Postmenopausal women: B-vitamin status

Choline functions in several important structural and cell signalling roles, integral in the formation of the phospholipids phosphatidylcholine and sphingomyelin, VLDL and the neurotransmitter acetylcholine ${ }^{(1)}$. Consequently, the metabolic implications of choline deficiency are wide ranging and severe and include fatty liver disease, DNA damage, cell apoptosis, altered gene expression and cognitive impairments ${ }^{(1,2)}$. The importance of choline as an essential nutrient was accepted in 1998 with the establishment in the USA of a cholineadequate intake (AI) of $550 \mathrm{mg} / \mathrm{d}$ for men and $425 \mathrm{mg} / \mathrm{d}$ for women ${ }^{(3)}$. The only other source of choline is via de novo synthesis from phosphatidylethanolamine by the enzyme phosphatidylethanolamine- $N$-methyltransferase, with $S$-adenosylmethionine as the methyl donor ${ }^{(4)}$, in a pathway enhanced by oestrogen activation of phosphatidylethanolamine- $N$-methyltransferase ${ }^{(5)}$. As a result, a woman's capacity to synthesise choline is likely to diminish after menopause and, consequently, dietary intake of choline is reported to assume much greater significance with respect to homocysteine metabolism and liver function in postmenopausal women ${ }^{(6,7)}$.

As a source of the methyl donor betaine, produced by oxidation of choline primarily in the liver, choline is important in the conversion of homocysteine to methionine. Remethylation of homocysteine occurs primarily via methionine synthase,

Abbreviations: AI, adequate intake; BHMT, betaine-homocysteine methyltransferase; DMG, dimethylglycine; EGRac, erythrocyte glutathione reductase activation coefficient; HRT, hormone replacement therapy; tHcy, total homocysteine.

*Corresponding author: Dr J. M. W. Wallace, fax +4428 7012 3023, email j.wallace@ulster.ac.uk 
using methylcobalamin (vitamin $\mathrm{B}_{12}$ ) as a cofactor and 5-methyltetrahydrafolate as a cosubstrate. However, remethylation also occurs via the betaine-homocysteine methyltransferase (BHMT) pathway, which requires betaine, with the importance of this pathway increased in the face of suboptimal folate status ${ }^{(8)}$. A high plasma concentration of total homocysteine (tHcy) is associated with an increased risk of a number of age-related diseases ${ }^{(9-14)}$, and although clinical trials have failed to confirm a causative link between elevated tHcy and CVD in patients with existing pathology ${ }^{(15,16)}$, interest remains on the potential for primary prevention of disease, particularly stroke ${ }^{(17,18)}$. Folic acid supplementation has been consistently shown to decrease $\mathrm{tHcy}^{(19)}$, with additional roles for vitamin $\mathrm{B}_{12}{ }^{(20)}$, vitamin $\mathrm{B}_{6}{ }^{(21)}$ and riboflavin ${ }^{(22)}$ identified. Betaine and choline intake and status are determinants of tHcy $^{(8,23,24)}$ and betaine supplementation can lower tHcy ${ }^{(25-28)}$. Studies suggest that plasma tHcy can be lowered postprandially in response to acute and short-term increases in choline intake ${ }^{(29,30)}$; however, effects on fasting plasma tHcy are equivocal.

Low choline intakes among adults have been reported previously $^{(24,31-33)}$ and indeed research reported from our own centre indicated that mean choline intakes among men and women aged 54-65 years were 172 (SD 72) mg/d, considerably lower than the $\mathrm{AI}^{(28)}$. Given the importance of choline in a wide range of physiological functions, together with consistent evidence of sub-optimal intakes, it has been suggested that the intake of choline-rich foods should be increased ${ }^{(34)}$. However, recent research ${ }^{(35)}$ which reported an association between choline status and risk of vascular disease would caution against such advice and rather highlights the need for more research into the physiological functions of this nutrient.

We assessed the effect on plasma concentrations of free choline, betaine and tHcy and on B vitamin status of choline supplementation at $1 \mathrm{~g} / \mathrm{d}$, a dose approximating to twice the current AI, over 12 weeks in healthy postmenopausal women, a group that would be expected to have a higher choline requirement. Previous research ${ }^{(36)}$ had reported that betaine and choline supplementation increased TAG concentration; therefore, this effect was also investigated.

\section{Methods \\ Participants}

Women aged 49-71 years were recruited to the study from within the University and from the local community. All interested subjects were interviewed regarding general health and well being and were considered eligible for screening if they were independently mobile and postmenopausal (defined as last spontaneous menstrual bleeding $>12$ months previously). The exclusion criteria were smoking, BMI $\geq 35 \mathrm{~kg} /$ $\mathrm{m}^{2}$, gastrointestinal, hepatic or renal disease, endocrine or metabolic abnormalities, use of drugs or dietary supplements known to influence B vitamin or choline status or metabolism, haematological disorder, serum vitamin $\mathrm{B}_{12}$ concentration $<111 \mathrm{pmol} / \mathrm{l}$ or serum creatinine concentration $\geq 130 \mu \mathrm{mol} / 1$. Initially, eighty-five postmenopausal women were recruited and following screening, forty-four women were deemed eligible to participate. This study was conducted according to the guidelines laid down in the Declaration of Helsinki and all procedures involving human subjects/patients were approved by the Research Ethical Committee of the University of Ulster. Written informed consent was obtained from all participants.

\section{Study design}

The study was a randomised, double-blind, placebo-controlled intervention trial undertaken during 2005-6. The sample size was estimated by using data for tHcy response to folic acid supplementation ${ }^{(37)}$. On the basis of the means and standard deviations of homocysteine response to treatments compared with that to placebo in this previous study, it was estimated that a sample size of nineteen subjects per group was needed to detect a difference of $1.8 \mu \mathrm{mol}$ homocysteine/1 with a power of $80 \%$ at $\alpha=0.05$. To allow for a $20 \%$ dropout rate, we estimated that a sample size of twenty-three subjects in each treatment group would be required.

Subjects were stratified according to reported use of hormone replacement therapy (HRT) and fasting tHcy and subjects in each stratum were randomised to receive $2.4 \mathrm{~g}$ choline bitartrate per $\mathrm{d}$ ( $1 \mathrm{~g}$ choline) or placebo ( $2.4 \mathrm{~g}$ tartaric acid per d) (Akzo Nobel Functional Chemicals). The supplement provided choline at approximately twice the AI of $425 \mathrm{mg} / \mathrm{d}$; research suggests that intakes higher than the current AI may be required to optimise choline status in postmenopausal women ${ }^{(7)}$. Each choline bitartrate capsule contained $250 \mathrm{mg}$ of choline and subjects were instructed to take two capsules twice a day with food. All supplements were identical in appearance and taste. To maximise compliance, supplements were distributed every 2 weeks in $7 \mathrm{~d}$ pillboxes. The pillboxes were then collected, and the number of unused tablets was recorded to monitor compliance. Volunteers were instructed not to consume any B vitamin or choline-containing supplements other than those provided, and were asked to maintain their usual diet and lifestyle throughout the intervention period. Previous research has reported the short-term effects of choline supplementation ${ }^{(38)}$. In contrast, we wished to investigate the longer-term effects of low-dose supplementation on tHcy and on lipid profile and, therefore, individuals were supplemented for 12 weeks. Weight (kg) and height (m) were measured at recruitment.

\section{Blood sampling and biochemical measurements}

Blood samples were collected at the Human Interventions Study Unit, University of Ulster at baseline, week 6 and week 12. Following an overnight fast $(12 \mathrm{~h})$, a blood sample was obtained from each participant. Blood samples were collected into EDTA-containing tubes for plasma and erythrocyte extraction and into a serum separation tube for serum extraction. The EDTA-containing tube was wrapped in foil (owing to the light sensitivity of a number of the analytes) and was placed on ice immediately after collection. Sample preparation 
and fractionation were performed within $0 \cdot 5-2 \cdot 5 \mathrm{~h}$ of the time of sampling as described in detail elsewhere ${ }^{(21)}$, and fractions were stored at $-70^{\circ} \mathrm{C}$ for batch analysis at the end of the study and at $-20^{\circ} \mathrm{C}$ for extraction of DNA.

Plasma free choline, betaine, tHcy, dimethylglycine (DMG) and methionine were analysed by liquid chromatographytandem MS as described previously ${ }^{(38)}$. Serum folate ${ }^{(39)}$ and vitamin $\mathrm{B}_{12}{ }^{(40)}$ were measured by microbiological assay. Plasma pyridoxal 5-phosphate (the main active derivative of vitamin $\mathrm{B}_{6}$ ) concentrations were determined by reversephase HPLC with fluorescence detection ${ }^{(41,42)}$. Riboflavin status was determined by erythrocyte glutathione reductase activation coefficient (EGRac), a functional assay which measures the activity of glutathione reductase before and after in vitro reactivation with its prosthetic group FAD; EGRac is calculated as a ratio of FAD stimulated to unstimulated enzyme activity with values $\leq 1.3$ generally considered to represent adequate riboflavin status ${ }^{(43)}$. For each participant, DNA was extracted using a QIAamp DNA Mini Kit (Qiagen Limited). Genotyping for the methylenetetrahydrofolate reductase $677 \mathrm{C} \rightarrow \mathrm{T}$ polymorphism was performed by PCR and Hinf1 digestion as described previously ${ }^{(42)}$.

Serum concentrations of total cholesterol, HDL-cholesterol and TAG were measured using a Hitachi 911 analyser (Roche) and enzymatic assays (Roche) and LDL-cholesterol concentrations were calculated ${ }^{(44)}$.

\section{Statistical analyses}

Data are presented as medians with 25 th and 75 th percentiles or means and standard deviations, as appropriate. Analysis of serum folate indicated a skewed distribution; therefore, data were transformed logarithmically to approximate normal distribution before statistical analyses. Baseline values for the placebo and choline groups were compared using an independent samples $t$ test or $\chi^{2}$ test, as appropriate. Bivariate relationships between choline and $\mathrm{B}$ vitamin-related measures were evaluated using Spearman's rank correlation coefficients. Data were analysed by repeated-measures ANOVA using the general linear model with choline/placebo as the betweensubject factor within time points. If there was a significant effect of treatment, specific contrasts were made using post hoc comparisons with Bonferroni's correction. To investigate if the response of tHcy to supplementation was dependent on baseline tHcy concentration or folate status, the intervention group was divided via median split into high $(>$ median) and low ( $\leq$ median) tHcy or serum folate and the analysis repeated. Statistical analyses were carried out using SPSS 17.0 for Windows (SPSS, Inc.). Results were considered statistically significant when $P<0 \cdot 05$.

\section{Results}

\section{Baseline characteristics and study compliance}

Of the forty-six individuals originally deemed eligible, four subjects did not complete the 12-week intervention and complete data sets were available for forty-two individuals, who were included in the final analysis. There were no significant differences in age, BMI, HRT use, concentration of tHcy, choline, betaine and B-vitamins between the choline and placebo groups at baseline (Table 1). The prevalence of the

Table 1. Characteristics and blood measurements of the volunteers at baseline (Mean values and standard deviations or medians with their 25th, 75th percentiles)

\begin{tabular}{|c|c|c|c|c|}
\hline & \multicolumn{2}{|c|}{ Choline ( $n$ 19) } & \multicolumn{2}{|c|}{ Placebo $(n 23)^{*}$} \\
\hline & Mean/median & sD/percentiles & Mean/median & sD/percentiles \\
\hline Age (years) & $60 \cdot 7$ & $5 \cdot 0$ & $59 \cdot 3$ & $5 \cdot 1$ \\
\hline BMI $\left(\mathrm{kg} / \mathrm{m}^{2}\right)$ & 26 & $3 \cdot 3$ & $25 \cdot 9$ & $2 \cdot 4$ \\
\hline Current use of HRT (\%) & \multicolumn{2}{|c|}{$31 \cdot 6$} & \multirow{2}{*}{\multicolumn{2}{|c|}{$26 \cdot 1$}} \\
\hline \multicolumn{3}{|l|}{ MTHFR genotype (\%) } & & \\
\hline CC & \multicolumn{2}{|c|}{$42 \cdot 1$} & \multicolumn{2}{|c|}{$43 \cdot 5$} \\
\hline CT & \multicolumn{2}{|c|}{47.4} & \multicolumn{2}{|c|}{$52 \cdot 2$} \\
\hline TT & \multicolumn{2}{|c|}{10.5} & \multicolumn{2}{|c|}{4.3} \\
\hline tHcy $(\mu \mathrm{mol} / \mathrm{l})$ & $9 \cdot 9$ & $9 \cdot 1,11 \cdot 4$ & $9 \cdot 7$ & $7 \cdot 5,11 \cdot 5$ \\
\hline Serum folate $(\mathrm{nmol} / \mathrm{l})$ & 23.5 & $14 \cdot 6,28 \cdot 9$ & $22 \cdot 5$ & $12 \cdot 5,32 \cdot 5$ \\
\hline Vitamin $B_{12}(\mathrm{pmol} / \mathrm{l})$ & 339 & 202,400 & 325 & 278,402 \\
\hline Plasma PLP (nmol//) & 20.4 & $16 \cdot 1,27 \cdot 8$ & $15 \cdot 5$ & $13 \cdot 2,25 \cdot 7$ \\
\hline Riboflavin EGRac† & 1.25 & $1 \cdot 18,1.35$ & 1.32 & $1.23,1.39$ \\
\hline Choline $(\mu \mathrm{mol} / \mathrm{l})$ & 7.33 & $5.94,8.14$ & $6 \cdot 85$ & $6 \cdot 12,7 \cdot 64$ \\
\hline Betaine $(\mu \mathrm{mol} / \mathrm{l})$ & $30 \cdot 7$ & $25 \cdot 5,39 \cdot 5$ & 28.9 & $24.4,33.9$ \\
\hline DMG $(\mu \mathrm{mol} / \mathrm{l})$ & 3.53 & $2 \cdot 98,4 \cdot 10$ & $3 \cdot 86$ & $3.13,4.54$ \\
\hline Met $(\mu \mathrm{mol} / \mathrm{l})$ & $23 \cdot 2$ & $21 \cdot 4,26 \cdot 6$ & $25 \cdot 5$ & $21 \cdot 1,27 \cdot 3$ \\
\hline Cholesterol (mmol/l) & $5 \cdot 85$ & 1.26 & 5.58 & 1.24 \\
\hline HDL-cholesterol $(\mathrm{mmol} / \mathrm{l})$ & 1.79 & 0.43 & 1.79 & 0.49 \\
\hline LDL-cholesterol (mmol/l) & 3.66 & 0.95 & $3 \cdot 30$ & 1.04 \\
\hline TAG $(\mathrm{mmol} / \mathrm{l})$ & 1.07 & 0.58 & 1.08 & 0.52 \\
\hline Glucose (mmol/l) & 4.78 & 0.54 & 5.08 & 0.58 \\
\hline
\end{tabular}

HRT, hormone replacement therapy; MTHFR, methylenetetrahydrofolate reductase; tHcy, total homocysteine; PLP pyridoxal 5-phosphate; EGRac, erythrocyte glutathione reductase activation coefficient; DMG, dimethylglycine. * The choline and placebo groups were not significantly different for any of the variables at baseline when examined using independent samples $t$ test or $\chi^{2}$ test as appropriate. †EGRac is a functional indicator of riboflavin status. 
methylenetetrahydrofolate reductase 677TT polymorphism did not differ significantly between the choline-supplemented ( $n$ 2) and placebo groups ( $n$ 1). On the basis of pill counts, the compliance of subjects with the study protocol was excellent ( $>95 \%$ of supplements were consumed by participants), with no reports of side effects of supplementation.

Baseline serum tHcy concentrations ranged from 4.62 to $19.8 \mu \mathrm{mol} / \mathrm{l}$; eighteen of the forty-two participants were classified as having an elevated tHcy, i.e. tHcy $>10 \mu \mathrm{mol} / \mathrm{l}^{(3)}$. A value of $7 \mathrm{nmol} / \mathrm{l}$ for serum folate has been reported as the cut-off point for negative folate balance ${ }^{(3)}$, and on this basis, no individual was classified as folate deficient. At baseline, no individual was found to be vitamin $\mathrm{B}_{12}$ deficient, i.e. no subject had a serum vitamin $B_{12}$ concentration $<120 \mathrm{pmol} / \mathrm{l}^{(3)}$. Vitamin $\mathrm{B}_{6}$ status as assessed by plasma pyridoxal 5-phosphate concentration at baseline ranged from $10 \cdot 1$ to $55.3 \mathrm{nmol} / 1$; and twenty-three $(55 \%)$ of the participants had low vitamin $\mathrm{B}_{6}$ status as defined by a plasma pyridoxal 5-phosphate concentration $<20 \mathrm{nmol} / \mathrm{l}^{(36)}$. Riboflavin deficiency, as defined by an EGRac value of $\geq 1 \cdot 3^{(8,45,46)}$, was evident in thirteen volunteers at baseline. Serum tHcy concentrations at baseline were significantly correlated with serum folate $(r-0.458 ; P=0.002)$, serum vitamin $\mathrm{B}_{12}$ ( $r-0.428 ; P=0.005)$, plasma creatinine $(r 0.392 ; P=0.01)$ and plasma methionine $(r-0.615 ; P=0.001)$, but not plasma vitamin $\mathrm{B}_{6}$ or riboflavin. At baseline, choline was positively associated with betaine $(r 0.389 ; P=0.011)$ but not DMG or tHcy, while betaine was positively associated with DMG ( $r$ 0.367; $P=0 \cdot 017)$.

At baseline, concentrations of free choline were higher among the $29 \%$ of women who reported HRT use compared to non-users; median ( 5 th, 95 th percentile) $7 \cdot 4(5 \cdot 2,12 \cdot 9) v \cdot 6 \cdot 9$
$(4 \cdot 8,9 \cdot 3) \mathrm{nmol} / \mathrm{l}$, a difference which approached statistical significance $(P=0.057$; independent samples $t$ test, data not shown).

\section{Intervention}

Table 2 shows the response of plasma concentrations of free choline, betaine, DMG, tHcy and methionine to 12-week choline $(1 \mathrm{~g} / \mathrm{d})$ supplementation. Repeated-measures ANOVA indicated that compared to placebo treatment, plasma choline at week $6(P=0.001)$ was significantly higher in the cholinesupplemented group, a difference that remained at week 12 $(P=0 \cdot 001)$, therefore, indicating a significant treatment effect between groups over time $F(1,39)=8 \cdot 65, P=0 \cdot 001$. In addition, plasma betaine was significantly higher following 6 weeks of choline supplementation, an effect that remained at week 12 $(P=0.001)$. There was a significant treatment effect in response to choline supplementation for betaine $F(1,39)=21 \cdot 55$, $P=0.0001$ and DMG $F(1,39)=6.04, P=0.005$ over 12 weeks At week 6 and week 12, there were no significant differences in tHcy or methionine concentrations in the choline-supplemented group compared to placebo. Serum folate, vitamin $\mathrm{B}_{12}$ and riboflavin status were not altered by choline supplementation; however, vitamin $\mathrm{B}_{6}$ status (as determined by plasma pyridoxal 5-phosphate) was significantly higher at week 12 in the choline-supplemented group compared to placebo $(P<0.01)$; however, there was no treatment effect in response to choline for vitamin $\mathrm{B}_{6}$ over time $F(1,39)=1.99$, $P=0 \cdot 17$ (Table 3).

The median (25th, 75 th percentile) change in plasma tHcy concentration at week 6 in the choline-supplemented group was $-0.9(-1.6,0.2) \mu \mathrm{mol}$, a change which when compared

Table 2. Response of plasma concentration of free choline, betaine, dimethylglycine (DMG), total homocysteine (tHcy) and methionine to 12 weeks of supplementation with $1 \mathrm{~g}$ choline/d in postmenopausal women

(Medians with their 25th and 75th percentiles)

\begin{tabular}{|c|c|c|c|c|c|c|c|c|}
\hline & \multicolumn{4}{|c|}{ Choline ( $n$ 19) } & \multicolumn{4}{|c|}{ Placebo (n 23) } \\
\hline & \multirow[b]{2}{*}{ Median } & \multirow[b]{2}{*}{ Percentiles } & \multicolumn{2}{|c|}{ Change from baseline } & \multirow[b]{2}{*}{ Median } & \multirow[b]{2}{*}{ Percentiles } & \multicolumn{2}{|c|}{ Change from baseline } \\
\hline & & & Median & Percentiles & & & Median & Percentiles \\
\hline \multicolumn{9}{|c|}{ Choline $(\mu \mathrm{mol} / \mathrm{l})$} \\
\hline Week 6 & $11 \cdot 7^{*}$ & $10 \cdot 5,13 \cdot 0$ & $4.7 \dagger$ & $3 \cdot 0,7 \cdot 0$ & 8.5 & $7 \cdot 4,10 \cdot 0$ & 1.5 & $0.8,3 \cdot 7$ \\
\hline Week 12 & $11 \cdot 1^{*}$ & $8 \cdot 1,13 \cdot 6$ & $4.2+t$ & $1.5,8.0$ & 8.7 & $6 \cdot 6,9 \cdot 4$ & 1.9 & $-0.3,3.2$ \\
\hline \multicolumn{9}{|c|}{ Betaine $(\mu \mathrm{mol} / \mathrm{l})$} \\
\hline Week 6 & $65 \cdot 0^{*}$ & $49 \cdot 9,80 \cdot 9$ & $29 \cdot 4 \dagger$ & $21 \cdot 0,42 \cdot 0$ & $31 \cdot 7$ & $25 \cdot 0,35 \cdot 1$ & 2.5 & $-2 \cdot 0,6 \cdot 7$ \\
\hline Week 12 & $54 \cdot 6^{*}$ & $35.0,75.9$ & $20 \cdot 1 \dagger \dagger$ & $10 \cdot 8,41 \cdot 4$ & $29 \cdot 6$ & $26 \cdot 2,37 \cdot 6$ & 0.7 & $-2 \cdot 0,7 \cdot 2$ \\
\hline \multicolumn{9}{|c|}{$\mathrm{DMG}(\mu \mathrm{mol} / \mathrm{l})$} \\
\hline Week 6 & $4 \cdot 63^{\star \star}$ & $4 \cdot 23,5 \cdot 22$ & $1.05 \dagger$ & $0.58,1.75$ & 3.64 & $3.21,4.46$ & -0.03 & $-0.61,0.40$ \\
\hline Week 12 & 3.92 & $3.55,5 \cdot 38$ & 0.69 & $0.34,1.28$ & 4.22 & $3 \cdot 21,4 \cdot 87$ & 0.22 & $-0.56,0.92$ \\
\hline \multicolumn{9}{|l|}{$\mathrm{tHcy}(\mu \mathrm{mol} / \mathrm{l})$} \\
\hline Week 6 & 9.5 & $8 \cdot 8,10 \cdot 7$ & -0.9 & $-1 \cdot 6,0.2$ & $10 \cdot 1$ & $8.9,11.4$ & 0.6 & $-0.4,1.9$ \\
\hline Week 12 & $9 \cdot 7$ & $8.9,11.4$ & -0.2 & $-1.5,1.1$ & $10 \cdot 0$ & $8.8,11.5$ & 0.8 & $-0 \cdot 7,2 \cdot 0$ \\
\hline \multicolumn{9}{|l|}{ Met $(\mu \mathrm{mol} / \mathrm{l})$} \\
\hline Week 6 & $24 \cdot 2$ & $22 \cdot 3,27 \cdot 5$ & 1.0 & $-2 \cdot 5,3 \cdot 8$ & $26 \cdot 7$ & $23 \cdot 2,28 \cdot 0$ & 1.3 & $-0.4,5.9$ \\
\hline Week 12 & $23 \cdot 8$ & $22 \cdot 6,25 \cdot 0$ & -0.2 & $-3 \cdot 1,2 \cdot 7$ & 24.9 & $23 \cdot 8,27 \cdot 1$ & -0.5 & $-1 \cdot 9,3 \cdot 4$ \\
\hline
\end{tabular}

Median values were significantly different from the placebo group at corresponding time point: ${ }^{*} P<0.001,{ }^{\star \star} P<0.05$.

Median values were significantly different from change in the placebo group at corresponding time point: $† P<0.001, \dagger \dagger P<0.01$ (repeated-measures ANOVA, and post hoc comparisons with Bonferroni's correction). 
Table 3. Response of B-vitamin status to 12 weeks of supplementation with $1 \mathrm{~g}$ choline/d in postmenopausal women (Medians with their 25th and 75th percentiles)

\begin{tabular}{|c|c|c|c|c|}
\hline & \multicolumn{2}{|c|}{ Choline ( $n$ 19) } & \multicolumn{2}{|c|}{ Placebo (n 23) } \\
\hline & Median & Percentiles & Median & Percentiles \\
\hline \multicolumn{5}{|l|}{ Serum folate $(\mathrm{nmol} / \mathrm{l})$} \\
\hline Week 12 & 24.5 & $16 \cdot 1,33 \cdot 2$ & $20 \cdot 5$ & $14 \cdot 3,28 \cdot 9$ \\
\hline Change from baseline & $2 \cdot 2$ & $-2 \cdot 0,8 \cdot 57$ & 0.8 & $-3 \cdot 0,5 \cdot 7$ \\
\hline \multicolumn{5}{|l|}{ Vitamin $\mathrm{B}_{12}(\mathrm{pmol} / \mathrm{l})$} \\
\hline Week 12 & 332 & 199,473 & 306 & 246,455 \\
\hline Change from baseline & 12 & $-34,99$ & -4 & $-60,45$ \\
\hline \multicolumn{5}{|l|}{ Plasma PLP (nmol/l) } \\
\hline Week 12 & $20 \cdot 6^{\star}$ & $18 \cdot 2,27 \cdot 6$ & $16 \cdot 1$ & $14 \cdot 2,20 \cdot 0$ \\
\hline Change from baseline & $2 \cdot 0$ & $-4 \cdot 9,7 \cdot 7$ & 0.3 & $-3 \cdot 7,4 \cdot 6$ \\
\hline \multicolumn{5}{|l|}{ Riboflavin EGRac† } \\
\hline Week 12 & 1.23 & $1 \cdot 17,1 \cdot 26$ & $1 \cdot 30$ & $1.24,1.37$ \\
\hline Change from baseline & -0.04 & $-0.1,0.05$ & 0.01 & $-0.09,0.09$ \\
\hline
\end{tabular}

PLP, pyridoxal 5-phosphate; EGRac, erythrocyte glutathione reductase activation coefficient.

* Median values were significantly different from the placebo group at corresponding time point $(P<0.01$, repeated-measures ANOVA, and post hoc comparisons with Bonferroni's correction).

†EGRac is a functional indicator of riboflavin status.

to the median change observed in the placebo group, $0 \cdot 6(-0 \cdot 4$, 1.9) $\mu \mathrm{mol}$, approached statistical significance ( $P=0.058$; independent samples $t$ test). Furthermore, the response to treatment was not significantly different in women with high $(>$ median, $9 \cdot 8 \mu \mathrm{mol} / \mathrm{l}) v$. low ( $\leq$ median) tHcy and comparing those with high ( $>$ median, $10 \mathrm{nmol} / \mathrm{l}) v$. low ( $\leq$ median) serum folate (data not shown).

There were no significant differences in plasma concentrations of total cholesterol, LDL-cholesterol, HDL-cholesterol, TAG or glucose at week 6 or week 12 in the choline-supplemented group compared to the placebo group (Table 4).

\section{Discussion}

To our knowledge, the present study is the first long-term, randomised, placebo-controlled intervention study to examine the effect of choline supplementation, not only on plasma
tHcy, but also on concentrations of free choline, betaine and DMG and on B-vitamin status. Although these variables are important with respect to the methionine cycle, they were not comprehensively reported in the previous intervention studies $^{(29,30,47)}$. The present results showed that long-term supplementation with $1 \mathrm{~g} / \mathrm{d}$ choline, as choline bitartrate, increased plasma free choline concentration, as well as concentrations of the choline metabolites, betaine and DMG. Supplementation resulted in a decrease in plasma tHcy after 6 weeks, which approached, but did not reach, statistical significance, possibly owing to the relatively high folate status and low tHcy of the present study population. In contrast to previous research ${ }^{(36)}$, we did not observe any significant adverse effect of choline supplementation on plasma lipid profiles.

In the present study, plasma choline, betaine and DMG concentrations at baseline appeared marginally lower than those

Table 4. Response of plasma lipids to 12 weeks of supplementation with $1 \mathrm{~g}$ choline/d in postmenopausal women* (Mean values and standard deviations)

\begin{tabular}{|c|c|c|c|c|c|c|c|c|}
\hline & \multicolumn{4}{|c|}{ Choline ( $n$ 19) } & \multicolumn{4}{|c|}{ Placebo (n 23) } \\
\hline & \multirow[b]{2}{*}{ Mean } & \multirow[b]{2}{*}{ SD } & \multicolumn{2}{|c|}{$\begin{array}{l}\text { Change from } \\
\text { baseline }\end{array}$} & \multirow[b]{2}{*}{ Mean } & \multirow[b]{2}{*}{ SD } & \multicolumn{2}{|c|}{$\begin{array}{l}\text { Change from } \\
\text { baseline }\end{array}$} \\
\hline & & & Mean & SD & & & Mean & SD \\
\hline \multicolumn{9}{|c|}{ Cholesterol (mmol/l) } \\
\hline Week 6 & $6 \cdot 29$ & 0.96 & 0.43 & 1.28 & $5 \cdot 84$ & 0.84 & 0.25 & 0.92 \\
\hline Week 12 & $6 \cdot 21$ & 0.99 & 0.42 & 1.29 & $5 \cdot 87$ & 0.90 & 0.13 & 0.47 \\
\hline \multicolumn{9}{|c|}{$\mathrm{HDL}-\mathrm{C}(\mathrm{mmol} / \mathrm{l})$} \\
\hline Week 6 & 1.88 & 0.39 & 0.08 & 0.41 & $1 \cdot 84$ & 0.44 & 0.06 & 0.34 \\
\hline Week 12 & $1 \cdot 81$ & 0.40 & 0.02 & 0.43 & 1.87 & 0.45 & 0.09 & 0.35 \\
\hline \multicolumn{9}{|c|}{ LDL-C (mmol/l) } \\
\hline Week 6 & $3 \cdot 85$ & 0.82 & 0.28 & 0.83 & 3.50 & 0.81 & 0.17 & 0.57 \\
\hline Week 12 & $3 \cdot 76$ & 1.01 & 0.22 & 0.92 & 3.50 & 0.84 & 0.06 & 0.39 \\
\hline \multicolumn{9}{|c|}{ TAG (mmol/l) } \\
\hline Week 6 & 1.24 & 0.62 & 0.16 & 0.44 & $1 \cdot 12$ & 0.47 & 0.03 & 0.27 \\
\hline Week 12 & 1.39 & 0.67 & 0.31 & 0.60 & $1 \cdot 22$ & 0.64 & 0.14 & 0.39 \\
\hline
\end{tabular}

HDL-C, HDL-cholesterol; LDL-C, LDL-cholesterol.

* There were no significant differences between treatment and placebo groups at baseline. No significant effect of treatment (repeatedmeasures ANOVA). 
reported previously ${ }^{(8,45,46)}$ and these may be explained by our measurement of fasting blood samples, in contrast to other studies. However, the lower values may also reflect the fact that the present study population comprised only postmenopausal women, who would be expected to have lower choline status owing to the loss of oestrogen, which naturally enhances choline synthesis ${ }^{(5)}$. In support of this contention, we did note that free choline concentration at baseline was higher in women who reported using HRT, a source of exogenous oestrogen. Recently, Fischer et al. ${ }^{(7)}$ reported that oestrogen treatment was associated with a decrease in the requirement for dietary choline among postmenopausal women. Folate has a betaine-sparing effect ${ }^{(48)}$ and folate status of the women in the present study was high. This observation is most probably explained by the wide availability of folic acid-fortified foods, which can contribute significantly to folate status ${ }^{(49)}$. Indeed, serum folate concentrations reported here were similar to values reported by us in a healthy adult cohort who habitually consumed between 40 and $98 \mu \mathrm{g}$ folic acid/d from fortified foods ${ }^{(49)}$. Plasma tHcy concentration was marginally lower than might have been expected among postmenopausal women; with only eighteen of the women observed to have a basal tHcy $>10 \mu \mathrm{mol} / \mathrm{l}$; again probably reflecting the generally high folate status of the study group. The inclusion of individuals who were regular consumers of fortified foods could be considered a limitation of our study design, in that such individuals would be less likely to respond to the homocysteine-lowering effect of choline. However, such individuals are representative of the general population in Northern Ireland, where over $75 \%$ consume foods fortified with folic acid and other B vitamins at least once per week ${ }^{(49)}$.

We observed a significant increase in circulating choline concentrations following supplementation with choline at a dose of $1 \mathrm{~g} / \mathrm{d}$, in the form of choline bitartrate. This dose would have resulted in a marked increase in dietary choline which we have recently estimated in a similar population to be approximately $300 \mathrm{mg} / \mathrm{d}^{(28)}$. Whether the significant effects on status observed in the present study would have been evident with lower doses of supplementation is not known; a previous dose-response intervention reported that while supplementation with $500 \mathrm{mg}$ choline/d, as choline chloride, did increase plasma free choline concentration, no effect was evident with $300 \mathrm{mg} / \mathrm{d}^{(47)}$. We also recorded significant increases in betaine and DMG concentrations post-supplementation. Although betaine can be obtained directly from the diet (with wholegrain cereals, spinach and beetroot being particularly good dietary sources $\left.{ }^{(50)}\right)$, it can also be formed from choline in a two-step enzymatic process, occurring in the liver and kidney, where choline is first oxidised to betaine aldehyde, and then further oxidised to betaine ${ }^{(51)}$. Our findings are in keeping with observational research showing that choline and betaine were positively associated ${ }^{(45)}$, and with an intervention study which also reported an increase in plasma betaine in men supplemented with choline ${ }^{(47)}$. BHMTmediated remethylation of homocysteine results in the conversion of betaine to DMG, and plasma betaine concentration was positively associated with DMG concentration in the present study. However, previous studies have reported that this association is only evident at lower DMG concentrations, a finding which the authors concluded was indicative of inhibition of BHMT by higher concentrations of $\mathrm{DMG}^{(45)}$. Supplementation had no significant effect on the concentration of folate, vitamin $\mathrm{B}_{12}$ or riboflavin, perhaps reflecting the overall adequate status of these nutrients. In contrast, supplementation was associated with a significant increase in vitamin $\mathrm{B}_{6}$, the status of which was low at baseline in just over half of the present study population. Observational research has previously reported an association between betaine and plasma vitamin $\mathrm{B}_{6}{ }^{(8)}$, and therefore the increase in vitamin $\mathrm{B}_{6}$ in the present intervention study may be owing to the higher betaine concentration observed following choline supplementation. Although our result is in keeping with the literature and scientifically plausible in respect of a $\mathrm{B}_{6}$-sparing effect with enhanced betaine status, we cannot however discount the possibility that this was a chance finding.

In the present study, choline supplementation for 6 weeks was accompanied by a modest effect in lowering plasma tHcy median (25th, 75th percentile) (\%) change in plasma tHcy concentration $(-0.9(-1 \cdot 6,0 \cdot 2) \mu \mathrm{mol} / \mathrm{l}(-9 \%), v \cdot 0 \cdot 6$ $(-0.4,1.9) \mu \mathrm{mol} / 1(6 \%)$ in the choline and placebo groups, respectively, $P=0.058)$. Phosphatidylcholine supplementation, providing $2.6 \mathrm{~g}$ choline/d, for 2 weeks was previously shown to significantly decrease fasting plasma tHcy by $3 \mu \mathrm{mol} / 1$ $(18 \%)^{(30)}$; however, the mean baseline tHcy concentration in that study was considerably higher than in the present intervention $(14.7 v \cdot 10 \cdot 1 \mu \mathrm{mol} / \mathrm{l})$. Indeed, subjects were recruited to the study of Olthof et al. ${ }^{(29)}$ on the basis of a high tHcy and were supplemented with a dose of choline that was two-and-a-half times higher than in our investigation, which may also explain the differing results. Previously, the consumption of a choline-rich meal, providing $760 \mathrm{mg}$ of choline, was associated with a lower plasma tHcy at $4 \mathrm{~h}$ post-meal ${ }^{(30)}$ In contrast to our study, the latter study showed no concomitant increase in plasma betaine, and, therefore, the authors concluded that the homocysteine-lowering effect was independent of the BHMT pathway and was possibly owing to a decrease in choline synthesis, which also generates homocysteine. Other researchers have reported that while choline intake did not alter fasting tHcy concentration, supplementation did attenuate the rise in plasma tHcy after a methionine $\operatorname{load}^{(47)}$, suggesting that the BHMT pathway of homocysteine remethylation may be more important in the fed state. Consequently, a more marked tHcy lowering may have been observed in the present study if non-fasting samples had been collected. The modest homocysteine-lowering effect with choline in this study may also be explained by the high folate status of our study population. Folate status was higher than in the two previously reported intervention studies $^{(29,30)}$, which is of note as it has been reported that the BHMT pathway of homocysteine remethylation comes into play only under conditions of impaired B-vitamin status ${ }^{(8,45)}$. In the present sample population, we did not exclude women on the basis of HRT use but rather stratified across groups by oestrogen use. Clearly, however, HRT composition and duration of use are likely to have varied 
and, therefore, given the established relationships among oestrogen, choline and tHcy, this may have confounded the response of thcy to supplementation.

The concomitant lowering in plasma tHcy, a reported risk factor for vascular disease ${ }^{(35)}$, with increased choline intake, might be predicted to lower disease risk; however, not all research $^{(23,32)}$ concurs with this contention. Indeed a very recent study by Wang et al. ${ }^{(35)}$, using a targeted metabolomics approach, concluded that plasma concentrations of choline, betaine and a subsequent metabolite, trimethylamine $\mathrm{N}$-oxide, were positively associated with the risk of vascular disease. However, while the authors found, using confirmatory animal studies, that gut microbiota metabolise choline into trimethylamine, which is converted into trimethylamine $\mathrm{N}$-oxide in the liver, they did not establish whether increased trimethylamine $\mathrm{N}$-oxide contributes directly to CVD progression or is simply a marker of disease risk. The authors did not observe any significant effect of choline on plasma cholesterol, TAG or glucose concentrations, in keeping with our findings. Earlier research indicated that choline, supplemented as phosphatidylcholine, increased plasma TAG concentrations $^{(36)}$, which was attributed to the role of phosphatidylcholine, as an obligate component of VLDL.

In conclusion, research has linked choline intake and status with a number of health conditions ${ }^{(52,53)}$, highlighting the benefits of optimal choline status. The present study shows that choline supplementation in postmenopausal women, at a dose approximately equivalent to twice the current $\mathrm{AI}$ for women, can significantly increase circulating free choline concentration as well as the concentration of the methyl donor betaine, and may also lower plasma tHcy. Despite the recent reports that excess dietary choline might lead to $\mathrm{CVD}^{(35)}$, choline is an essential nutrient for several key metabolic pathways, and consequently, we caution, as have others ${ }^{(54)}$ that strategies to lower choline for therapeutic purposes should proceed with care.

\section{Acknowledgements}

The authors wish to thank all the women who participated in the present study. The authors also acknowledge Dr Ian Bradbury for his advice on statistical analysis. This study was supported by the Department of Employment and Learning, Northern Ireland. Akzo Nobel Functional Chemicals supplied the choline supplements and placebo capsules. J. M. W. W. was involved in hypothesis generation, organisation of the study, statistical analysis, data interpretation and manuscript preparation. P. M. W. and M. E. D. were responsible for execution of the study, sample collection and biochemical analysis. J. J. S., J. M. M., H. M., M. W., M. P. B. and P. J. R. assisted in hypothesis generation, study design and data interpretation. A. M. M., J. M. S. and P. M. U. were involved in sample analysis and data interpretation. All authors read and approved the manuscript. No author had any conflict of interest.

\section{References}

1. Ueland PM (2010) Choline and betaine in health and disease. $J$ Inherit Metab Dis 34, 3-15.
2. Zeisel SH (2004) Nutritional importance of choline for brain development. J Am Coll Nutr 23, 621S-626S.

3. Institute of Medicine (IOM) (1998) Dietary Reference Intakes for Thiamin, Riboflavin, Niacin, Vitamin $B_{6}$, Folate, Vitamin $B_{12}$, Pantothenic Acid, Biotin, and Choline. Washington, DC: National Academies Press.

4. Dudman NP, Guo XW, Gordon RB, et al. (1996) Human homocysteine catabolism: three major pathways and their relevance to development of arterial occlusive disease. J Nutr 126, 1295S-1300S.

5. Drouva SV, LaPlante E, Leblanc P, et al. (1986) Estradiol activates methylating enzyme(s) involved in the conversion of phosphatidylethanolamine to phosphatidylcholine in rat pituitary membranes. Endocrinology 119, 2611-2622.

6. Fischer LM, daCosta KA, Kwock L, et al. (2007) Sex and menopausal status influence human dietary requirements for the nutrient choline. Am J Clin Nutr 85, 1275-1285.

7. Fischer LM, da Costa KA, Kwock L, et al. (2010) Dietary choline requirements of women: effects of estrogen and genetic variation. Am J Clin Nutr 92, 1113-1119.

8. Holm PI, Hustad S, Ueland PM, et al. (2007) Modulation of the homocysteine-betaine relationship by methylenetetrahydrofolate reductase $677 \mathrm{C} \rightarrow \mathrm{t}$ genotypes and B-vitamin status in a large-scale epidemiological study. J Clin Endocrinol Metab 92, 1535-1541.

9. Wald DS, Law M \& Morris JK (2002) Homocysteine and cardiovascular disease: evidence on causality from a metaanalysis. BMJ 325, 1202.

10. Haan MN, Miller JW, Aiello AE, et al. (2007) Homocysteine, $B$ vitamins, and the incidence of dementia and cognitive impairment: results from the Sacramento Area Latino Study on Aging. Am J Clin Nutr 85, 511-517.

11. McLean RR, Jacques PF, Selhub J, et al. (2008) Plasma B vitamins, homocysteine, and their relation with bone loss and hip fracture in elderly men and women. J Clin Endocrinol Metab 93, 2206-2212.

12. Kivipelto M, Annerbo S, Hultdin J, et al. (2009) Homocysteine and holo-transcobalamin and the risk of dementia and Alzheimers disease: a prospective study. Eur J Neurol 16, 808-813

13. Kohaar I, Kumar J, Thakur N, et al. (2010) Homocysteine levels are associated with cervical cancer independent of methylene tetrahydrofolate reductase gene (MTHFR) polymorphisms in Indian population. Biomarkers 15, 61-68.

14. van den Kommer TN, Dik MG, Comijs HC, et al. (2010) Homocysteine and inflammation: predictors of cognitive decline in older persons? Neurobiol Aging 31, 1700-1709.

15. Marti-Carvajal AJ, Sola I, Lathyris D, et al. (2009) Homocysteine lowering interventions for preventing cardiovascular events. The Cochrane Database Systematic Reviews, issue 4, CD006612.

16. Clarke R, Halsey J, Lewington S, et al. (2010) Effects of lowering homocysteine levels with B vitamins on cardiovascular disease, cancer, and cause-specific mortality: meta-analysis of 8 randomized trials involving 37485 individuals. Arch Intern Med 170, 1622-1631.

17. Wang X, Qin X, Demirtas H, et al. (2007) Efficacy of folic acid supplementation in stroke prevention: a meta-analysis. Lancet 369, 1876-1882.

18. Lee M, Hong KS, Chang SC, et al. (2010) Efficacy of homocysteine-lowering therapy with folic acid in stroke prevention: a meta-analysis. Stroke 41, 1205-1212.

19. Homocysteine Lowering Trialists' Collaboration (2005) Dosedependent effects of folic acid on blood concentrations of homocysteine: a meta-analysis of the randomized trials. Am J Clin Nutr 82, 806-812. 
20. Eussen SJ, de Groot LC, Clarke R, et al. (2005) Oral cyanocobalamin supplementation in older people with vitamin $\mathrm{B}_{12}$ deficiency: a dose-finding trial. Arch Intern Med 165, $1167-1172$.

21. McKinley MC, McNulty H, McPartlin J, et al. (2001) Low-dose vitamin B-6 effectively lowers fasting plasma homocysteine in healthy elderly persons who are folate and riboflavin replete. Am J Clin Nutr 73, 759-764.

22. McNulty H, Dowey LRC, Strain JJ, et al. (2006) Riboflavin lowers homocysteine in individuals homozygous for the MTHFR $677 \mathrm{C} \rightarrow \mathrm{T}$ polymorphism. Circulation 113, 74-80.

23. Cho E, Zeisel SH, Jacques P, et al. (2006) Dietary choline and betaine assessed by food-frequency questionnaire in relation to plasma total homocysteine concentration in the Framingham Offspring Study. Am J Clin Nutr 83, 905-911.

24. Lee JE, Jacques PF, Dougherty L, et al. (2010) Are dietary choline and betaine intakes determinants of total homocysteine concentration? Am J Clin Nutr 91, 1303-1310.

25. Schwab U, Torronen A, Toppinen L, et al. (2002) Betaine supplementation decreases plasma homocysteine concentrations but does not affect body weight, body composition, or resting energy expenditure in human subjects. Am J Clin Nutr 76, 961-967.

26. Olthof MR, van Vliet T, Boelsma E, et al. (2003) Low dose betaine supplementation leads to immediate and long term lowering of plasma homocysteine in healthy men and women. J Nutr 133, 4135-4138.

27. Atkinson W, Slow S, Elmslie J, et al. (2009) Dietary and supplementary betaine: effects on betaine and homocysteine concentrations in males. Nutr Metab Cardiovasc Dis 19, 767-773.

28. Price RK, Keaveney EM, Hamill LL, et al. (2010) Consumption of wheat aleurone-rich foods increases fasting plasma betaine and modestly decreases fasting homocysteine and LDL-cholesterol in adults. J Nutr 140, 2153-2157.

29. Olthof MR, Brink EJ, Katan MB, et al. (2005) Choline supplemented as phosphatidylcholine decreases fasting and postmethionine-loading plasma homocysteine concentrations in healthy men. Am J Clin Nutr 82, 111-117.

30. Atkinson W, Elmslie J, Lever M, et al. (2008) Dietary and supplementary betaine: acute effects on plasma betaine and homocysteine concentrations under standard and postmethionine load conditions in healthy male subjects. $A m J$ Clin Nutr 87, 577-585.

31. Chiuve SE, Giovannucci EL, Hankinson SE, et al. (2007) The association between betaine and choline intakes and the plasma concentrations of homocysteine in women. Am J Clin Nutr 86, 1073-1081.

32. Dalmeijer GW, Olthof MR, Verhoef P, et al. (2008) Prospective study on dietary intakes of folate, betaine, and choline and cardiovascular disease risk in women. Eur J Clin Nutr 62, 386-394.

33. Xu X, Gammon MD, Zeisel SH, et al. (2009) High intakes of choline and betaine reduce breast cancer mortality in a population-based study. FASEB J 23, 4022-4028.

34. Zeisel SH, Da Costa KA, Franklin PD, et al. (1991) Choline, an essential nutrient for humans. FASEB J 5, 2093-2098.

35. Wang Z, Klipfell E, Bennett BJ, et al. (2011) Gut flora metabolism of phosphatidylcholine promotes cardiovascular disease. Nature 472, 57-63.

36. Olthof MR, van Vliet T, Verhoef P, et al. (2005) Effect of homocysteine-lowering nutrients on blood lipids: results from four randomised, placebo-controlled studies in healthy humans. PLoS Med 2, e135.
37. Ward M, McNulty H, McPartlin J, et al. (1997) Plasma homocysteine, a risk factor for cardiovascular disease, is lowered by physiological doses of folic acid. QJM 90, 519-524.

38. Holm PI, Ueland PM, Kvalheim G, et al. (2003) Determination of choline, betaine, and dimethylglycine in plasma by a high-throughput method based on normal-phase chromatography-tandem mass spectrometry. Clin Chem 49, 286-294.

39. Molloy AM \& Scott JM (1997) Microbiological assay for serum, plasma, and red cell folate using cryopreserved, microtiter plate method. Methods Enzymol 281, 43-53.

40. Kelleher BP \& Broin SD (1991) Microbiological assay for vitamin $\mathrm{B}_{12}$ performed in 96-well microtitre plates. J Clin Pathol 44, 592-595.

41. Bates CJ, Pentieva KD, Matthews N, et al. (1999) A simple, sensitive and reproducible assay for pyridoxal 5'-phosphate and 4-pyridoxic acid in human plasma. Clin Chim Acta 280, 101-111.

42. Frosst P, Blom HJ, Milos R, et al. (1995) A candidate genetic risk factor for vascular disease: a common mutation in methylenetetrahydrofolate reductase. Nat Genet 10, 111-113.

43. Powers HJ, Bates CJ, Prentice AM, et al. (1983) The relative effectiveness of iron and iron with riboflavin in correcting a microcytic anaemia in men and children in rural Gambia. Hum Nutr Clin Nutr 37, 413-425.

44. Friedewald WT, Levy RI \& Fredrickson DS (1972) Estimation of the concentration of low-density lipoprotein cholesterol in plasma, without use of the preparative ultracentrifuge. Clin Chem 18, 499-502.

45. Holm PI, Ueland PM, Vollset SE, et al. (2005) Betaine and folate status as cooperative determinants of plasma homocysteine in humans. Arterioscler Thromb Vasc Biol 25, 379-385.

46. Konstantinova SV, Tell GS, Vollset SE, et al. (2008) Divergent associations of plasma choline and betaine with components of metabolic syndrome in middle age and elderly men and women. J Nutr 138, 914-920.

47. Veenema K, Solis C, Li R, et al. (2008) Adequate intake levels of choline are sufficient for preventing elevations in serum markers of liver dysfunction in Mexican American men but are not optimal for minimizing plasma total homocysteine increases after a methionine load. Am J Clin Nutr 88, 685-692.

48. Melse-Boonstra A, Holm PI, Ueland PM, et al. (2005) Betaine concentration as a determinant of fasting total homocysteine concentrations and the effect of folic acid supplementation on betaine concentrations. Am J Clin Nutr 81, 1378-1382.

49. Hoey L, McNulty H, Askin N, et al. (2007) Effect of a voluntary food fortification policy on folate, related B vitamin status, and homocysteine in healthy adults. Am J Clin Nutr 86, $1405-1413$

50. USDA (2008) US Department of Agriculture Database for the Choline Content of Common Foods. Release Two. Beltsville, MD: US Department of Agriculture.

51. Ueland PM, Holm PI \& Hustad S (2005) Betaine: a key modulator of one-carbon metabolism and homocysteine status. Clin Chem Lab Med 43, 1069-1075.

52. Xu X, Gammon MD, Zeisel SH, et al. (2008) Choline metabolism and risk of breast cancer in a population-based study. FASEB J 22, 2045-2052.

53. Bjelland I, Tell GS, Vollset SE, et al. (2009) Choline in anxiety and depression: the Hordaland Health Study. Am J Clin Nutr 90, 1056-1060.

54. Rak K \& Rader DJ (2011) Cardiovascular disease: the dietmicrobe morbid union. Nature 472, 40-41. 